\title{
Lymphoma of the Base of the Tongue: An Incidental Finding on the Preoperative Workup for a Spine Surgery
}

\author{
Mohammad Sami Walid
}

\begin{abstract}
Lymphoma of the tongue is very rare and accounts for $1 \%$ of all malignant tumors of the oral cavity. We present a patient who presented with weakness and difficulties with ambulation who was a known cervical spine spondylosis and stenosis patient. During the preoperative workup for cervical spine surgery a tumor at the base of the tongue was discovered which was confirmed by pathology to be a lymphoma.
\end{abstract}

Keywords: Lymphoma; Tongue; Spine surgery; Preoperative workup

\section{Case Report}

Lymphoma of the tongue is very rare and accounts for $1 \%$ of all malignant tumors of the oral cavity [1-5]. We present a 73 year-old Caucasian man with history of hypertension, chronic obstructive pulmonary disease, and hyperlipidemia who presented in 2008 because of weakness and was ambulating using a walker. In 2004, he was diagnosed with multilevel cervical spondylosis, moderate spinal stenosis at $\mathrm{C} 3-\mathrm{C} 4$ with bilateral foraminal stenosis and central disk protrusion at $\mathrm{C} 5-\mathrm{C} 6$. He was also found to have a moderateto-severe stenosis at L3-L5. He was a lifelong smoker with nearly a 100 pack-year history. On admission he had low sodium $(128 \mathrm{mEq} / \mathrm{L})$. A postadmission MRI shows a moderately advanced multilevel spondylosis most pronounced at $\mathrm{C} 3-\mathrm{C} 4$ with prominent disc bulge causing moderate cord impingement (Fig. 1). The myelogram shows an apparent

Manuscript accepted for publication June 30, 2009

Medical Center of Central Georgia, 840 Pine Street, Suite 880, Macon, GA 31201, USA. Email: mswalid@yahoo.com

doi:10.4021/jocmr2009.07.1251 block in the central spinal canal at the $\mathrm{C} 3-\mathrm{C} 4$ level with grade I anterolisthesis at the same level and degenerative changes throughout the mid and lower cervical spine.

During the preoperative medical exam, the patient states he has been also having sore throat, night sweats, and shortness of breath. For the sore throat, an Ear-Nose-Throat consultation is requested. Laryngoscopy shows a smooth mucosa-covered mass in the right half of the base of the tongue. Pathological study of the biopsy reveals grade II/ III follicular lymphoma, positive for B cell clonality. Neck CT is ordered which shows a soft tissue mass in the right hypopharynx extending from the base of the tongue into the posterior prevertebral musculature (Fig. 2). Scattered lymph nodes along the internal jugular chain on the right as well as nodes around the submandibular gland are noticed on CT, however, none of these exceeds a centimeter in diameter and there are almost as many subcentimeter nodes in the same location on the left side. The patient undergoes anterior cervical decompression and fusion at $\mathrm{C} 3-4$ and is discharged to follow up with otolaryngology.

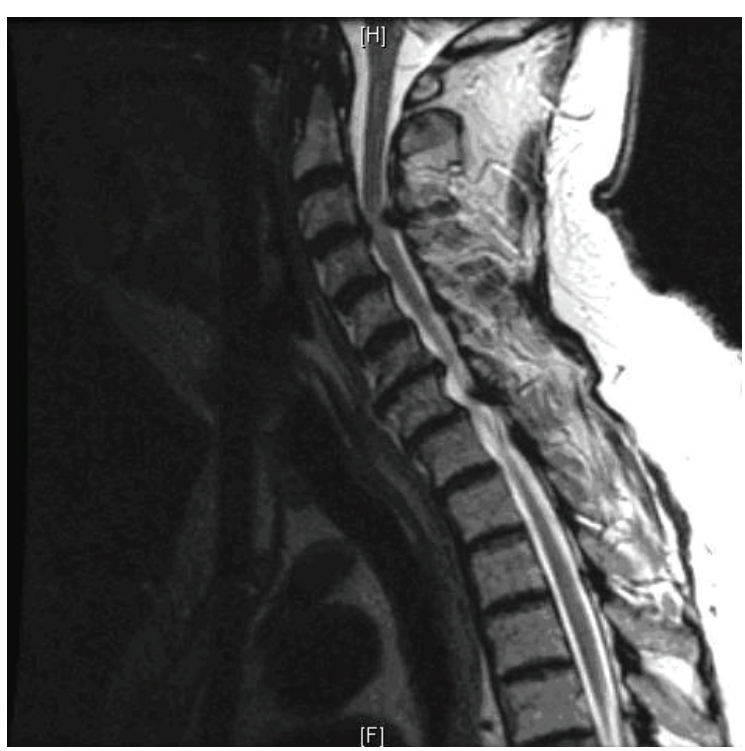

Figure 1. MRI T2 of the cervical spine showing multilevel spondylosis and moderate cord impingement at C3-C4. 


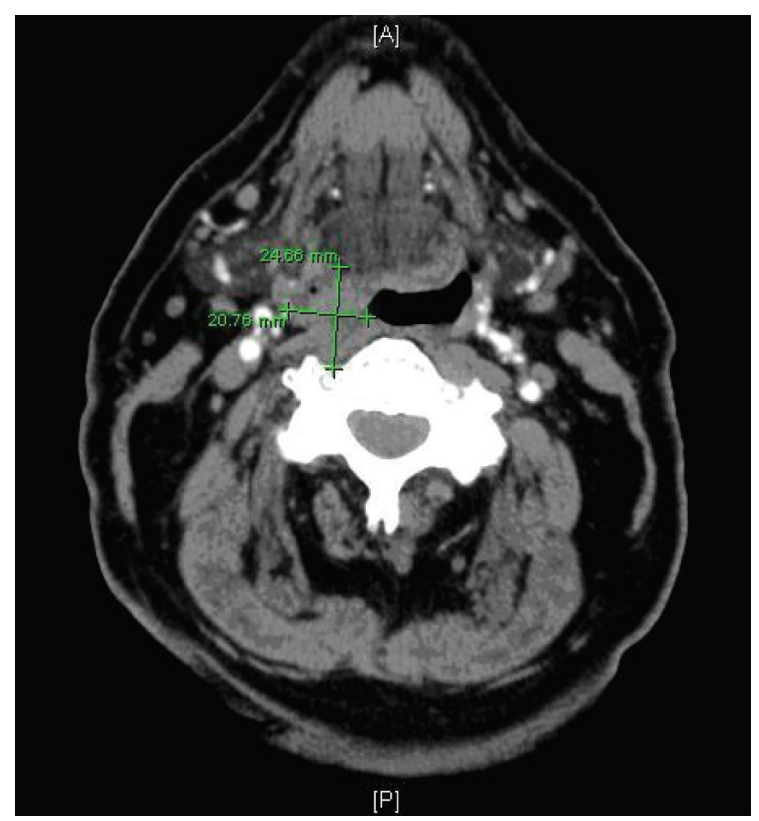

Figure 2. Neck CT with contrast showing a soft density mass in the right hypopharynx lateral wall extending around the lateral pharyngeal wall into the prevertebral soft tissues on the right.

In this patient, the weakness was caused by the cervical canal stenosis and worsened by hyponatremia as a sign of a paraneoplastic syndrome caused by the lymphoma. This case illustrates the importance of performing laryngoscopy in elderly patients during the preoperative workup for any major surgery if they complain of sore throat and shortness of breath with a lifelong history of smoking [1]. Unfortunately, we read our patient's obituary in the local newspaper eight months later.

\section{References}

1. Dolgonos L, Janssen WJ. A 75-year-old woman with dyspnea and a sore throat. Chest 2008;133(4):10141020.

2. Derk CT, Conway RT, Jimenez SA. Primary B-cell lymphoma of the tongue in a patient with systemic sclerosis. Oral Oncol 2004;40(1):103-106.

3. Dey P, Luthra UK, Sheikh ZA, Mathews SB. Fine needle aspiration cytology of primary non-Hodgkin's lymphoma of the tongue. A case report. Acta Cytol 1999;43(3):422-424.

4. Talmon Y, Gilbey P, Falah R, Samet A, Cohen H, Khoury J. Primary B cell lymphoma of the tongue. Isr Med Assoc J 2007;9(10):755-756.

5. Yaris N, Kutluk T, Akcoren Z, Yalcin B, Gogus S, Buyukpamukcu M. Primary non-Hodgkin lymphoma of the tongue in a child. Med Pediatr Oncol 1998;30(6):372373. 